\title{
PLANE: A Platform for Negotiation of Multi- attribute Multimedia Objects
}

\author{
${ }^{1}$ Rharon M. Guedes, ${ }^{1}$ Marcus R. Laurentino, ${ }^{1}$ Carlos S. Dias, ${ }^{1}$ Alisson V. Brito \\ ${ }^{1}$ Centro de Informática, Universidade Federal da Paraíba (UFPB), João Pessoa, Brazil
}

\begin{abstract}
This work proposes the definition of a system to negotiate products in an e-commerce scenario. This negotiation system is defined as PLANE - Platform to Assist Negotiation - and it is carried in a semi-automatic way, using multi-attributes functions, based on attributes of the negotiated content. It also presents an architecture to interconnect the participant through an inter-network in the television broadcasters context. Each participant of the inter-network applies policies for its own contents, and all of them must comply these policies. If a participant needs a content not covered by the policies, it is possible to start a negotiation process for this specific content. Experiments present a simulation scenario where PLANE assists the negotiation between three sellers and one buyer with predefined negotiation profiles. Results demonstrated the success of the system in approximate the negotiator after some few interactions, reducing time and cost.
\end{abstract}

Keywords - e-commerce, negotiation, inter-network, multi-attribute, multimedia.

\section{INTRODUCTION}

C Turrently television broadcasters produce and keep a large amount of audiovisual content that is distributed between their commercial partners [1]. However the distribution and trading of this material involve complex contractual negotiations between television broadcasters, like contracts signing, rights and duties establishment, are applied to the negotiated content [2]. Furthermore, the search and content acquisition from another broadcasters have have been prove a hard tasks, due a lack of an efficient infrastructure that provides means to broadcasters connect and negotiate their content.

In these circumstances, the definition of a negotiation system to share audiovisual content of television broadcasters with other partners is relevant, providing the means to negotiate the content, respecting the contractual policy established. More than that, the procedures of negotiation must be performed in a semi-automated way, in order to overcome the delay caused by negotiations made by people.

This work aims to define a negotiation system to share content by television broadcasters. To support it, a logical architecture to interconnect broadcasters was defined, creating an inter-network of broadcasters. Also within the inter-network it is possible to negotiate one or more audiovisual contents among two or more participants through the module called PLANE. This module considers attributes extracted from the content negotiated, like price, number of views and resolution, to generate offers and counteroffers in a negotiation session between two or more participants in the content negotiation.

In Section 2 are presented some related work in audiovisual content sharing and negotiation using a semi-automatic away. In Section 3 is presented the architecture to support the internetwork concept of television broadcasters and its services. In Section 4 the PLANE is shown, a mechanism for semiautomated negotiation of content in the inter-network. In Section 5, one scenario of negotiation with PLANE is presented together with results. In Section 6 the conclusion is presented altogether with ideas for future work.

\section{RELATED WORKS}

In [2], it was proposed the AXMEDIS framework to integration, production and distribution of digital content. The AXMEDIS creates a P2P network of digital content producers where content negotiation is possible through $\mathrm{B} 2 \mathrm{~B}$ or $\mathrm{B} 2 \mathrm{C}$.

In the context of negotiation the approach presented in [3], which is an extended work of [15], presents improvements related to the semi-automatic way of negotiation, such as the number of attributes considered in negotiation and the utilization of a formal rule to generate an offer proposal.

According to [16] many of the problems faced by [15] are solved, but it is limited to the use of static attributes in the agreements, not being possible to consider other attributes. Another approach was presented in [4], adapting the concepts of [5] to the context of that work: the use of multi-value functions and weighted attributes, where the latter represents the degree of relevance given by a negotiator. Besides these works, the work of [17] treats the negotiation using one or more attributes, but like [15], actually, the negotiation is made using only one attribute, in this case, the price

\section{BROADCASTER INTER-NETWORK}

Although it would be easily applied to any kind of product of an e-commerce context, as a case of study, this work focuses on audiovisual content negotiation and sharing through the definition of an inter-network of broadcasters, where the participants select and publish their contents to be shared and negotiated with other participants connected to the internetwork.

In the architecture proposed here, the connection with other participants of the inter-network are made through PCE (Point of Content Exchange). In a simple comparison, a PCE 
resembles a router, because it is located in the edge of the network, making the connection with other possible participants of the inter-network. Also the PCE is responsible for other functions, like the management of policies, shared content and the negotiation of some content published to the inter-network. Figure 1 presents the architecture of the PCE and its components.

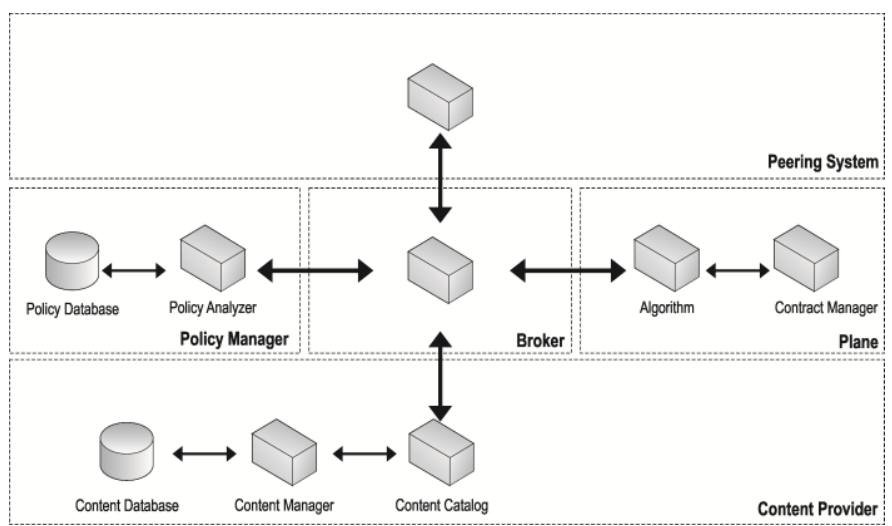

Fig. 1 - Point of Content Exchange (PCE) architecture

There are several metadata standards to deal with, like MPEG-21 [9], PBCore [10], TV-Anytime [11], making integration of DAM (Digital Asset Management) systems a complex task, because it is necessary to understand the semantics of the attributes defined in metadata, to make consistent relations between two different metadata standards [7].

The Negotiation System is the focus of this work. In this component occurs the effective negotiation among two or more participants of the inter-network. The negotiation module is called PLANE (PLatform to Assist NEgotiation), which is composed by a Contract Manager and an algorithm for negotiation. The components of a PCE are described as following.

\section{A. Peering system}

The Peering System is responsible for managing the connections of the PCEs in the inter-network. It includes the discovering of other PCEs, the establishment of connections and selecting which connection each data flow (search, negotiation, control, contracts, etc.) uses.

Thus, the Peering System establishes and maintains the topology of the inter-network, i.e., it defines an Internet television network, established in application level under an existing distribution infrastructure such as the Internet. Therefore, the inter-network is an overlay network that performs application-level infrastructure over a physical communication [19].

\section{B. Broker}

The Broker is responsible for controlling the information flow between the components of the PCE, dispatching requests from the Peering System, receives requests to verify of policies, access content from a particular participant, transmitting necessary attributes in a negotiation, and so on.

\section{Policy Manager}

The Policy Manager role is to define and validate the permissions established by the participants of the shared contents in the inter-network. For example, a policy can be defined to a particular content does not appear in a search result made by other participants in the inter-network.

Policies are defined using a specification language called XACML [8]. The manager of the broadcaster choose the content that will be shared in the inter-network and adds a standard policy for the content being made available. A standard policy deals with the actions that participants can perform with a shared content, without necessarily start a negotiation. For instance, a policy can state that any participant in the can view a particular audiovisual content, but only the low quality version. If a high-quality version is more suitable, the content holder should be contacted for a direct negotiation.

\section{Content Provider}

The Content Provider is responsible for performing the integration and management of content provided by each broadcaster participant in the inter-network. This integration is necessary because each broadcaster has its own system of asset management [19], which may have different metadata standards, video formats and other features for multimedia storage [20][23].

Thus, the shared content are categorized in a standardized way to facilitate traffic information in the inter-network. To this catalog new attributes can also be added, as the price of a given content, information that is relevant to the trading system.

\section{E. Negotiation system}

In this component occurs effectively the bargaining between two participants in the inter-network: one in the role of seller and the other as buyer of the shared content. It consists of a Contract Manager and an algorithm for negotiation. The algorithm analyzes and creates new bids, does counter-offers and effectively conducts the negotiation of digital content between the two participants. This negotiation starts only when any participant is interested in buying a specific content of one of the other participants. This content would not be available directly because of some restriction in default policies that were initially established by the Policy Manager.

Once the negotiation is made, the Contract Manager is responsible for defining the contract in XML, concretizing this negotiation. This contract template is a generic XML, so it can be exported to other contract models, using a Rights Expression Language (REL). For this study we used the ODRL (Open Digital Rights Language), due to the fact it is an open-source language, community-supported, flexible and extensible. It was developed to express licenses on digital objects in a value chain of producers, distributors and consumers, adding security and control over the negotiated content [21].

So far, we describe an architecture for interconnecting television broadcasters in order to create an inter-network, where it is possible to integrate content from broadcasters, policy specification for sharing these contents and the 
mechanisms for negotiation between participants of different contents. The next sessions will be focused on the negotiation system called PLANE.

\section{PLANE}

For negotiation effectively occurs, it was developed an algorithm that is responsible for generating a set of offerings and counter-offerings, where its main goal is an agreement that brings gains for all parties involved in the negotiation. To understand the operation of the algorithm, prior knowledge of some concepts is necessary: what is an attribute, multi-attribute functions and the weight given to an attribute.

According to [12], attributes can be defined as the characteristics of a product. They can be concrete, observable or measurable of relevant importance. Another more general meaning is given by [13], which defines the attribute as a characteristic qualitative or quantitative of an observed member, in other words, each property that defines an object or entity. The algorithm presented here will focus only on quantitative characteristics.

The negotiation decision can be weighted by a single attribute, but situations like this are not as common. The most frequent problems require the measurement of more than one attribute [14].

The weight corresponds to the degree of importance that a negotiator (buyer or seller) defines to the attribute. It is a value in the range from 0 (least important) to 1 (most important). However it could be any other continuous range (with values belonging to the set of real numbers) that can be transformed into a percentage scale.

\section{A. Functions}

According to [4], the usage of Value Functions and Utility Functions is necessary for a negotiation tool to formulate possible decision options, where both specify a unique structure of preference. The Value Functions are a particular case of a Utility Function and is embedded in an environment of certainty; a Utility Function can also handle systems involving an environment of luck. In this paper, it was considered only Value Functions. The negotiation process also considers more than one attribute, so here functions with multi-attribute values are used. With this type of functions, it is possible to manipulate the impact of changing attributes throughout the process, making the negotiation flow faster and more efficient.

According to this criterion, three functions were used: a Linear Function, the Total Value Function and the Displacement Function, all adapted to our scenario. The functions are shown as following.

\subsubsection{Linear Function}

The Linear Function is used to normalize the different kinds of values for the attributes and is defined as:

Linear $=\frac{A V w-A V d}{A V w-A V b}$

Where:
$\mathrm{AVw} \rightarrow$ Worst attribute value

$\mathrm{AVb} \rightarrow$ Best attribute value

$\mathrm{AVd} \rightarrow$ Desired attribute value

\subsubsection{Displacement Function}

One of the challenges of this work was to define how much the algorithm would spread the values of the attributes to launch a new bid into the interval initially defined by the negotiators, aiming always to present an better bid than the offered before. The Displacement Function was based on the model of [3] and is defined as following:

$F d=|(A V b-A V w) *(1-\alpha)|$

Where:

$\mathrm{AVb} \rightarrow$ Best attribute value

$\mathrm{AVw} \rightarrow$ Worst attribute value

$\alpha \mathrm{i} \rightarrow$ Weight of attribute

\subsubsection{Total Value Function}

After normalization of the attribute values, the function defined by [4] was used, called Total Value Function (FVT), which is defined by the sum of the Value Function (here is the Linear Function) of each attribute multiplied by the weight of each attribute. The FVT is presented as following:

$F_{\text {wt }}=\sum_{i=1}^{n} \alpha_{i} F_{\text {linear }}(i)$

Where:

$\mathrm{i} \rightarrow$ Content of attribute

$\alpha \mathrm{i} \rightarrow$ Weight of attribute

$\mathrm{F}_{\text {linear }} \rightarrow$ Linear Function of the attribute

\section{B. Offer Validation}

Using the mathematical concept of combinatorics, the algorithm is able to generate new offers to be proposed to the buyers. To do this, the algorithm uses the offer that is desired by the sellers as base to perform variations and then generated new ones to the buyers.

As stated before, content can have several attributes, which can be classified as qualitative or quantitative. To generate a different offer, there must be a variation of at least one of the possible attributes of the content in negotiation.

Before performing a variation in an offer, it is necessary to know how much could be that variation of an attribute in a negotiation. To do so, it is necessary to calculate the Displacement Function. In our scenario, it is considered three attributes, generating 27 combinations of variations of these attributes to be processed and suggested to the participants of the negotiation.

Finally, a validation is still necessary, because the algorithm needs to generate an offer that is within the limits and interests of the buyer. As soon as an offer is generated, an analysis is done to ensure that all the offers fit the buyer's needs. 


\section{V.EXPERIMENTS}

The simulation described in this section analyzes the feasibility of the negotiation algorithm with different amounts of buyers and sellers. To validate the algorithm, we developed a scenario composed of three sellers and one buyer. In this scenario, the negotiation was divided into three separate negotiations between one buyer and one seller. Suppose one negotiator wishes to purchase a video related to the final match of volleyball of the Olympic in Athens, 2004, in order to conduct a retrospective and make a comparison with the actual team, which will compete in the Olympic Games of Rio, 2016. The initial offer of the negotiator was to buy the media and its broadcasting rights by $\$ 500$, with permission to exhibits it 13 times with a resolution of $720 \mathrm{p}$ (resolution of $1280 \times 720$ ). Lastly, the negotiator was configured as a hard negotiator; in other words, he is very conservative and seeks a counter-offer very close to what he defined initially. Tables 1 and Table 2 show the settings used for the buyer and the sellers, respectively.

TABLE I

CONFIGURATION OF THE BUYER FOR THE NEGOTIATION

\begin{tabular}{lcccc}
\hline \hline Attribute & Worst value & Best value & Desired value & Weight \\
\hline Price & $\$ 650$ & $\$ 480$ & $\$ 500$ & 0.5 \\
Exhibition & 10 & 20 & 13 & 0.3 \\
Resolution & $720 \mathrm{p}$ & $1080 \mathrm{p}$ & $720 \mathrm{p}$ & 0.2 \\
\hline \hline
\end{tabular}

TABLE II

CONFIGURATION AND EVALUATION OF THE SELLERS FOR THE NEGOTIATION

\begin{tabular}{clccccc}
\hline \hline Seller & Attributes & $\begin{array}{c}\text { Worst } \\
\text { value }\end{array}$ & $\begin{array}{c}\text { Best } \\
\text { value }\end{array}$ & $\begin{array}{c}\text { Desired } \\
\text { value }\end{array}$ & Weight & $\begin{array}{c}\text { Total } \\
\text { Value } \\
\text { Function }\end{array}$ \\
\hline \multirow{2}{*}{1} & Price & $\$ 700$ & $\$ 500$ & $\$ 600$ & 0.6 & \\
& Exhibition & 12 & 24 & 13 & 0.3 & 0.266 \\
& Resolution & $480 \mathrm{p}$ & $720 \mathrm{p}$ & $720 \mathrm{p}$ & 0.1 & \\
\hline \multirow{2}{*}{2} & Price & $\$ 600$ & $\$ 480$ & $\$ 480$ & 0.5 & \\
& Exhibition & 9 & 19 & 10 & 0.3 & 0.494 \\
& Resolution & $480 \mathrm{p}$ & $720 \mathrm{p}$ & $720 \mathrm{p}$ & 0.2 & \\
\hline \multirow{2}{*}{3} & Price & $\$ 640$ & $\$ 500$ & $\$ 550$ & 0.4 & \\
& Exhibition & 13 & 21 & 16 & 0.4 & 0.601 \\
\hline \hline
\end{tabular}

Still considering this scenario, it was made another setting in algorithm to generate 20 new valid counter-offers. However, this will occur only in the best case, and in the worst case, no bid may be generated if the counter-offers are off the determined range by the negotiators. Counter-offers whose values do not exceed the limits proposed by the negotiators involved and are within the percentage of the selected profile by the buyer are considered valid. The valid counter-offers are sorted in descending order, in relation to the difference between the Total Value Function of the sellers and the buyer. Table 3 shows the top five offers generated for each seller participating in the negotiation.

TABLE III

TOP FIVE OFFERS GENERATED BY PLANE

\begin{tabular}{ccccccc}
\hline \hline Buyer & $\begin{array}{c}\text { Offer } \\
\text { number }\end{array}$ & Price & Exhibition & Resolution & TVF & $\begin{array}{c}\text { TVF } \\
\text { differ. }\end{array}$ \\
\hline \multirow{4}{*}{1} & 1 & $\$ 595$ & 14 & $720 \mathrm{p}$ & 0.512 & $17.2 \%$ \\
& 2 & $\$ 500$ & 13 & $720 \mathrm{p}$ & 0.725 & $17.0 \%$ \\
& 3 & $\$ 505$ & 13 & $720 \mathrm{p}$ & 0.712 & $15.0 \%$ \\
& 4 & $\$ 510$ & 13 & $720 \mathrm{p}$ & 0.700 & $13.0 \%$ \\
& 5 & $\$ 590$ & 15 & $720 \mathrm{p}$ & 0.550 & $11.2 \%$ \\
\hline
\end{tabular}

\begin{tabular}{ccccccc}
\hline & 1 & $\$ 498$ & 19 & $720 \mathrm{p}$ & 0.894 & $44.4 \%$ \\
2 & 2 & $\$ 496$ & 18 & $720 \mathrm{p}$ & 0.886 & $43.1 \%$ \\
& 3 & $\$ 494$ & 17 & $720 \mathrm{p}$ & 0.878 & $41.8 \%$ \\
& 4 & $\$ 492$ & 16 & $720 \mathrm{p}$ & 0.870 & $40.4 \%$ \\
& 5 & $\$ 490$ & 15 & $720 \mathrm{p}$ & 0.861 & $39.1 \%$ \\
\hline \multirow{3}{*}{3} & 1 & $\$ 525$ & 16 & $720 \mathrm{p}$ & 0.558 & $9.8 \%$ \\
& 2 & $\$ 520$ & 16 & $720 \mathrm{p}$ & 0.572 & $7.5 \%$ \\
& 3 & $\$ 515$ & 16 & $720 \mathrm{p}$ & 0.587 & $5.2 \%$ \\
& 4 & $\$ 510$ & 16 & $720 \mathrm{p}$ & 0.607 & $2.9 \%$ \\
& 5 & $\$ 550$ & 19 & $720 \mathrm{p}$ & 0.637 & $2.8 \%$ \\
\hline \hline
\end{tabular}

Only offers 4 and 5 of Seller 3 are valid. This is evidenced by the percentage obtained by these two bids, since they are lower than the percentage of the buyer profile, which is considered hard with acceptance of $5 \%$ variation. Table 4 presents a summary of the negotiation between the Buyer 1 and the sellers after the execution of negotiation by PLANE.

TABLE IV

SUMMARY OF THE NEGOTIATION BETWEEN THE BUYER 1 AND THE SELLERS

\begin{tabular}{ccccccc}
\hline \hline Buyer & $\begin{array}{c}\text { Offer } \\
\text { number }\end{array}$ & Price & Exhibition & Resolution & TVF & $\begin{array}{c}\text { TVF } \\
\text { differ. }\end{array}$ \\
\hline \multirow{2}{*}{1} & 1 & $\$ 600$ & 20 & $720 \mathrm{p}$ & 0.649 & 0.030 \\
& 2 & $\$ 480$ & 10 & $720 \mathrm{p}$ & 0.494 & 0.005 \\
& 3 & $\$ 510$ & 16 & $720 \mathrm{p}$ & 0.607 & 0.012 \\
\hline
\end{tabular}

For Seller 2 was maintained the offer before the execution of the algorithm. The counter-offer presented to the Sellers 1 and 3 were generated by PLANE, showing improvements, enabling greater probability of agreement between Buyer 1 and the sellers.

Finished this scenario, it is evident that from a negotiation with one buyer and $\mathrm{N}$ sellers, it is possible to generate offers for all parties involved individually. Eventually, the Buyer chooses among the offers generated by the three sellers, according to its judgment.

\section{A. Scenario Analysis}

The simulation scenario showed that the PLANE was able to generate new counter-offers for the negotiation, either one to one (1-1), one to many (1-N) or many to many $(\mathrm{N}-\mathrm{N})$, after performing the necessary transformations. In the simulation scenario, the generated counter-offers were more improved rather than the offers presented initially. As the algorithm is semi-automated it does not make decisions with respect to the negotiation closing, it is up to the Buyer choose with which seller he close the negotiation. Figure 2 shows the prices and the number of rounds necessary for the generation of the new counter-offers to all involved sellers.

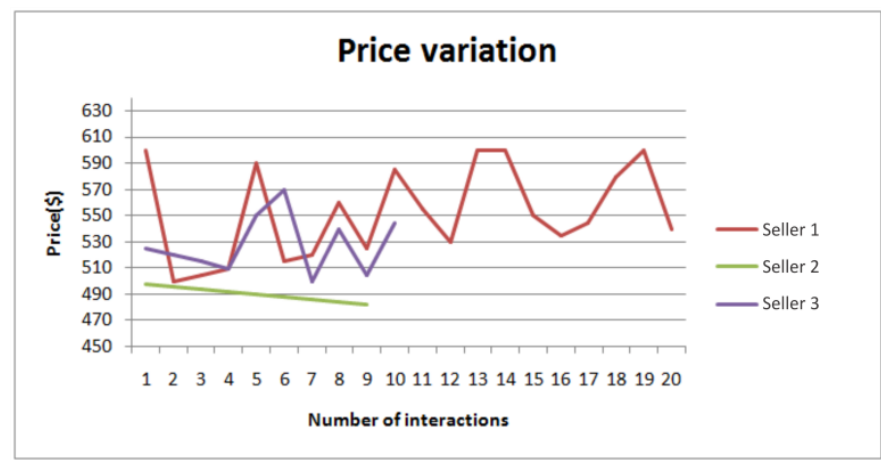

Fig. 2 - Price variation during negotiation 
For Seller 1, despite being generated 20 valid negotiations, the chosen offer maintained the previous values for the price and resolution, which were $\$ 600.00$ and $720 \mathrm{p}$ respectively. The only attribute changed was the amount of exhibition, from 13 to 20 , taking 13 interactions to find a counter-offer within the selected profile. For Seller 2 the offer was maintained as previous one, since the PLANE failed to obtain improvements over the original offer. For Seller 3, who originally asked $\$ 550.00$ for the rights to exhibit the videos, achieved a reduction of $\$ 40.00$, closing the negotiation for $\$ 510.00$. The other attributes were maintained with its initial values. Figure 3 presents the values for the Total Value Function before and after execution of PLANE.

Total Value Function before and after execution of PLANE

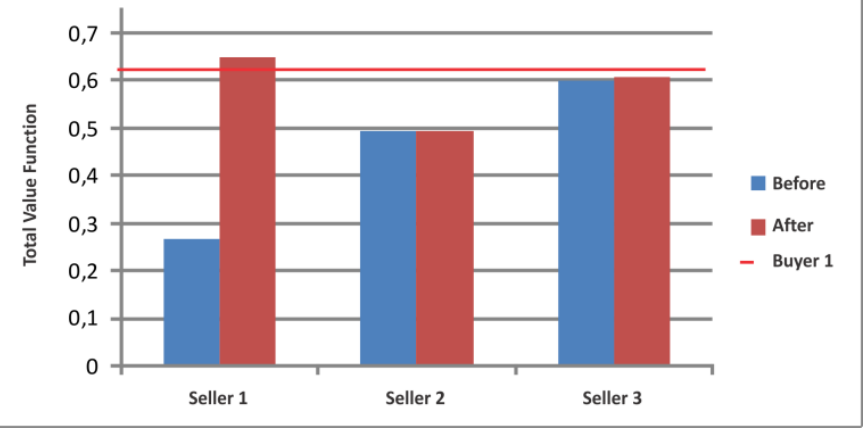

Fig. 3 - Total Value Function before and after execution of PLANE

It can be observed from Figure 3 that further approximation of the FVT value of sellers with the buyer was 0.619. For example, the Seller 1 had FVT 0.266 before negotiation, with a difference of 0.353 to the Buyer, after negotiation this difference dropped to 0.03 . For Seller 2, the algorithm did not achieve improvements. In contrast, for Seller 3, the difference decreased from 0.018 to 0.012 . In the end, the Buyer might choose with which seller he will close the deal. Thus, the PLANE brings together the interests of the negotiators involved, even selecting the profile of a hard negotiator. In practice, PLANE can reduce the negotiation time, even when the deal is not directly closed, always bringing the negotiators to offers that somehow benefit all of involved.

\section{CONCLUSION AND FUTURE WORKS}

This paper presents an extension of a proposal for a negotiation system that was applied for audiovisual content (see [22]). This negotiation system is implemented in a semiautomated way, using multi-attribute functions and quantitative weighing of attributes to better negotiate the terms of a possible deal. Using PLANE can bring some advantages such as reducing the time to reach an agreement, semiautomatic negotiation allows for multiple participants. Sometimes the algorithm fails to generate valid offers or there may be biased depending on the values added to the product attributes in negotiation.

As a future research the use of other multi-attributes functions in order to increase the efficiency of the negotiations is being investigated. Furthermore, how to choose the attributes dynamically at the time of negotiation is also being investigated, giving more freedom for both buyer and the seller.

\section{ACKNOWLEDGMENT}

This research was supported and sponsored by CAPES, Brazil (Coordenação de Aperfeiçoamento de Pessoal de Nível Superior).

\section{REFERENCES}

[1] Glasman, K., Peregudov, A., Lichakov, V., Shetinin, B. Television Broadcast Networks: from centralized automation control to distributed computing. Broadcasterpapers.com. Published in 29 June 2003.

[2] Bellini, P., Bruno, I., Nesi, P. An Architecture of Automating Production of Cross Media Content for Multi-Channel Distribution. In First International Conference on Automated Production of Cross Media Content for Multi-Channel Distribution (AXMEDIS'05). Florence, Italy, 2005. pp. 123-133.

[3] Faratin, P. et al. Designing Responsive and Deliberative Automated Negotiators. In Proceedings of Workshop of Automated Negotiation. Barcelona, 1999.

[4] Néri, E. L., Dahia M. L. M. Implementing a mechanism of integrative negotiation: challenges and results (in Portuguese). Operational Research v.24, 2004

[5] Raiffa, H. The Art \& Science of Negotiation. Harvard University Press, Massachusetts, 1982.

[6] Lung, N., Mak, P., Wan-cheng, N., Lian-chen, L., Cheng, W. A Semiautomated Negotiation Process to Improve the Usability for Online Marketplaces. In 7th IEEE International Conference on Computer and Information Technology (CIT 2007). October 16-19, 2007. pp. 253258.

[7] Tous, R., Carreras, A., Delgado, J., Cordara, G., Gianluca, F., Peig, E. An architecture for TV content distributed search and retrieval using the MPEG query format (MPQF). In Proceedings of the 2008 AmbiSys workshop on Ambient media delivery and interactive television (AMDIT '08). ICST, Brussels, Belgium, 2008.

[8] OASIS. XACML 2.0 Specification Set. 2005. Available at http://www.oasis-open.org

[9] ISO/IEC. ISO/IEC 21000-5/FPDAM 1- MPEG-21 - Part 5: Rights Expression Language, Amendment 1: MPEG-21 REL profiles.

[10] Public Broadcasting Metadata Dictionary Project (PBCore). Available at http://www.utah.edu/cpbmetadata

[11] TV-Anytime Forum. Available at http://www.tv-anytime.org

[12] Tiecher, A. Identify product attributes in the smartphone market that add value as perceived by students of School of Management Federal University of Rio Grande do Sul (in Portuguese), 2011. Available at: www.lume.ufrgs.br/bitstream/handle/10183/33341/000787035.pdf

[13] Ferreira, A. The New Aurélio Dictionary of Portuguese Language (in Portuguese). 3th ed. Positivo, 2004.

[14] Baily, P. et al. Shopping: Principles and Management (in Portuguese). São Paulo, Brazil. Ed. Atlas, 2000.

[15] Chavez A.; Maes P. Kasbah: An Agent Marketplace for Buying and Selling Goods. Massachusetts Institute of Technology, 1996.

[16] De Paula, Gustavo Eliano. Modelo de Negociação Bilateral para Comércio Eletrônico. 2004. Dissertação (Mastar Thesis) Universidade Federal de Pernambuco, Centro de Informática, Recife.

[17] Ngai Lung; Mak, P.; Ni Wan-cheng; Liu Lian-chen; Wu Cheng; , "A Semi-automated Negotiation Process to Improve the Usability for Online Marketplaces," Computer and Information Technology, 2007. CIT 2007. 7th IEEE International Conference on, vol., no., pp.253258, 16-19 Oct. 2007

[18] UCHOA, D. C. et al. An Overlay Application-Layer Multicast Infrastructure. International Conference on Advanced Information Networking and Applications. Bradford, United Kingdom, 2009. pp. 233-240.

[19] Austerberry, D. Digital Asset Management. 2. ed. Oxford: Elsevier, 2006. $352 \mathrm{p}$ 
International Journal of Artificial Intelligence and Interactive Multimedia, Vol. 2, $N^{o} 4$.

[20] Blanken, H. M. Multimedia Retrieval. 1. ed. Nova Iorque: Springer, 2007. $372 \mathrm{p}$.

[21] ODRL. Open Digital Rights Language, 2002. Disponivel em: <http://odrl.net/1.1/ODRL-11.pdf〉. Acesso em: 08 de agosto de 2012.

[22] Gonzalez-Cresp, Rubén, et al. Dynamic, ecological, accessible and 3D Virtual Worlds-based Libraries using OpenSim and Sloodle along with mobile location and NFC for checking in. 2012. International Journal of Interactive Multimedia. Vol. 1 (7) pp 62-69. DOI: 10.9781/ijimai.2012.177

[23] Maia, R.; Dias, C.; Laurentino, M. R.; Brito, A. V.; "A Semi-automatic Negotiation Strategy for Multi-attribute and Multiple Participants". In: Álvaro Rocha, Ana Maria Correia, Tom Wilson, Karl A. Stroetmann. (Org.). Advances in Intelligent Systems and Computing. 22 ed. Berlin: Springer Berlin Heidelberg, 2013, v. 206, p. 885-892.
Rharon M. Guedes is researcher from Laboratory of Video Applications (LAViD). He received his Master degree in Computer Science from Federal University of Paraiba (UFPB) in 2013. His research interests are in Multimedia Applications, Digital Television and Sofware Development.

Marcus R. Laurentino is undergraduate student of Computer Science at Federal University of Paraiba (UFPB). He participates of Laboratory of Video Applications (LAViD).

Carlos S. Dias is assistant professor at Federal University of Paraiba (UFPB) and advances PhD Studies in Computer Engineering from Federal University of Rio Grande do Norte (UFRN). He is researcher of Laboratory of Video Applications (LAViD). His research interests are in Computer Networks, Digital Television, Video Transmission and Operating Systems.

Alisson V. Brito is associate professor at Federal University of Paraiba (UFPB), Brazil. He received Doctorate degree in electrical engineering from the Universidade Federal de Campina Grande (UFCG) in the field of microelectronics in cooperation with the University of Karlsruhe in Germany (2008). He is currently a member of the program committees of Journals and Conferences. He has experience in computer science with emphasis in computer systems architecture and embedded systems, acting on the following topics: simulation, computer education, embedded systems, and computer architecture. 